\title{
PÓS-TRATAMENTO DE LIXIVIADO DE ATERRO SANITÁRIO POR FILTRAÇÃO DIRETA ASCENDENTE EM PEDREGULHO
}

\author{
Eduardo Hideo Fuji \\ Daniele Satie Koga \\ Yorgos Noleto Coutroutsos \\ Emília Kiyomi Kuroda
}

RESUMO: Nos últimos anos, o aumento significativo de resíduos sólidos domiciliares depositados em aterros sanitários tem ocasionado a formação de subprodutos como o lixiviado, de cor escura, odor desagradável e composição variável e complexa, sendo nocivo ao meio ambiente quando lançado indiscriminadamente em corpos hídricos. $\mathrm{O}$ presente trabalho teve como objetivo avaliar a aplicabilidade da técnica de filtração direta ascendente em pedregulho como pós-tratamento de lixiviado de aterro sanitário. A eficiência foi avaliada por meio de análises das amostras coletadas no efluente do filtro ascendente em pedregulho. Os parâmetros físicos e químicos avaliados foram pH, perda de carga na camada filtrante, frente de impurezas e cor aparente. Foi aplicada uma taxa de $15 \mathrm{~m}^{3} \mathrm{~m}^{2} \mathrm{dia}^{-1}$, dosagem de $400 \mathrm{mg} \mathrm{L}^{-1}$ de ferro (cloreto férrico) e $630 \mathrm{mg} \mathrm{L}^{-1}$ de $\mathrm{HCl}$ para controle do pH em 4,0. A carreira de filtração teve duração de $24,0 \mathrm{~h}$, cuja eficiência de remoção de cor aparente variou de $99,1 \%$ a $99,6 \%$, restando um valor residual de 37,9 e 15,9 uH, respectivamente. A filtração direta ascendente em pedregulho mostrou ser eficiente com relação à remoção de cor, necessitando da continuidade de estudo para confirmar sua aplicabilidade no pós-tratamento de lixiviado, visando à diminuição dos impactos ambientais e riscos à saúde pública. 
Palavras-chave: Lixiviado. Filtração direta ascendente. Tratamento.

\section{INTRODUÇÃO}

A produção de resíduos sólidos domiciliares e industriais tem aumentado significativamente nos últimos anos, devido à mudança do estilo de vida da população, ao crescimento industrial, comercial e populacional e ao desenvolvimento tecnológico. Paralelamente, a destinação final dos mesmos tem sido uma das maiores preocupações mundiais.

O aterro sanitário continua sendo o principal método de disposição final de resíduos, especialmente em países em desenvolvimento, pois apresenta vantagens econômicas quando comparado com os métodos de incineração, compostagem, entre outros. Além da viabilidade econômica, o aterramento sanitário minimiza as agressões ambientais e permite uma decomposição controlada de resíduos até a transformação em material inerte e estabilizado (RENOU et al., 2008).

O inconveniente do método de aterragem é a formação de subprodutos, como o gás metano e o lixiviado, denominado também de chorume ou percolado. Decomposições físicas, químicas e biológicas de resíduos sólidos depositados promovem a formação destes subprodutos que são solubilizados em água, sendo nocivos ao meio ambiente (DINIZ, 2010).

O lixiviado é um líquido escuro com odor desagradável, o qual possui uma composição variável e complexa, a depender do tipo de resíduo sólido, idade do aterro, grau de compactação, entre outros fatores. Em geral, contém altas concentrações de matéria orgânica (biodegradável e refratária), constituída principalmente de substâncias húmicas, além de concentrações de nitrogênio amoniacal, metais pesados, orgânicos clorados e sais inorgânicos (RENOU et al., 2008).

Quando lançado indiscriminadamente nos mananciais, o lixiviado pode provocar a eutrofização do meio estimulando a proliferação de algas, o decréscimo do 
oxigênio dissolvido, bem como o aumento da toxidade à comunidade aquática, quando o nitrogênio estiver na forma de amônia (DINIZ, 2010).

Desta forma, o tratamento de lixiviado proveniente de aterros sanitários tem grande relevância ambiental, econômica e social, principalmente porque o volume de resíduos gerados vem crescendo em ritmo mais acelerado que o crescimento da população. Além disso, legislações ambientais estão cada vez mais restritivas tanto à preservação de águas subterrâneas e superficiais quanto aos padrões de lançamento de efluente.

Em face da necessidade de um sistema de tratamento que enquadre a qualidade do lixiviado aos padrões estabelecidos nas legislações vigentes, o estudo da filtração direta ascendente em pedregulho merece investigação, tendo em vista seu alto desempenho para o tratamento de água para consumo humano (MEGDA et al., 1999; CESAR et al., 2000; GUSMÃO, 2001; KURODA, 2002; KURODA, 2006).

A filtração direta ascendente possui algumas vantagens, como redução do consumo de coagulante, menor área requerida, melhor aproveitamento da camada filtrante, realização da filtração no sentido da camada de maior para a de menor granulometria, carreiras de filtração mais longas e melhor aproveitamento da carga hidráulica disponível (AZEVEDO NETO, 1970).

Além disso, dentre as várias alternativas de filtros em pedregulho, a filtração vertical com escoamento ascendente apresenta a vantagem de maior capacidade de retenção de sólidos no fundo do filtro, de onde podem ser mais facilmente removidos através da execução de descargas de fundo, além de resultar em durações de carreiras mais prolongadas (KURODA, 2002).

As características e vantagens da filtração direta ascendente para tratamento de água para consumo humano, de acordo com Kuroda (2002), são ilustradas na Tabela 1. 
Tabela 1 - Características e vantagens do sistema de filtração ascendente para tratamento de água

\begin{tabular}{ll}
\hline CARACTERíSTICA & VANTAGEM \\
\hline $\begin{array}{l}\text { Filtração no sentido da camada de maior } \\
\text { granulometria para a de menor }\end{array}$ & $\begin{array}{l}\text { Utilização da altura total da camada. Diminuição da perda de } \\
\text { carga. Carreiras de filtração mais longas }\end{array}$ \\
\hline $\begin{array}{l}\text { Coagulação química no mecanismo de } \\
\text { adsorção-neutralização de cargas }\end{array}$ & $\begin{array}{l}\text { Utilização de menores quantidades de coagulante e produção } \\
\text { de menor quantidade de lodo }\end{array}$ \\
\hline $\begin{array}{l}\text { Dispensa as unidades de floculação e } \\
\text { decantação }\end{array}$ & Menor área e custo de implantação \\
\hline $\begin{array}{l}\text { Possibilita a execução de descarga de } \\
\text { fundo }\end{array}$ & $\begin{array}{l}\text { Eficiente método de remoção do material retido na camada } \\
\text { suporte. Efluentes de melhor qualidade. Carreiras de filtração } \\
\text { mais prolongadas }\end{array}$ \\
\hline
\end{tabular}

Fonte: KURODA (2002)

Kuroda (2002) ressaltou que os custos de operação e manutenção são significativamente menores quando comparados aos de uma instalação na qual são usados a coagulação, floculação, decantação e filtração, devido à redução do consumo de energia, do emprego de mão-de-obra, da quantidade de coagulante utilizado e menor produção de lodo. Além disso, o custo de uma construção de uma estação de tratamento de água utilizando a técnica de filtração direta ascendente, abastecendo 170.000 habitantes, pode ser cerca de 2,5 vezes menor que a de uma estação de ciclo completo (DI BERNARDO, 1993).

Diante do exposto, o objetivo do presente trabalho foi estudar a aplicabilidade da técnica de filtração direta ascendente em pedregulho como póstratamento de lixiviado de aterro sanitário, em relação à remoção de matéria orgânica correlacionada à cor aparente.

\section{DESENVOLVIMENTO}

2.1

Material e métodos 
O experimento em instalação piloto e as análises foram realizados no Laboratório de Saneamento da Universidade Estadual de Londrina - UEL. A Figura 1 apresenta o fluxograma de processo do experimento.

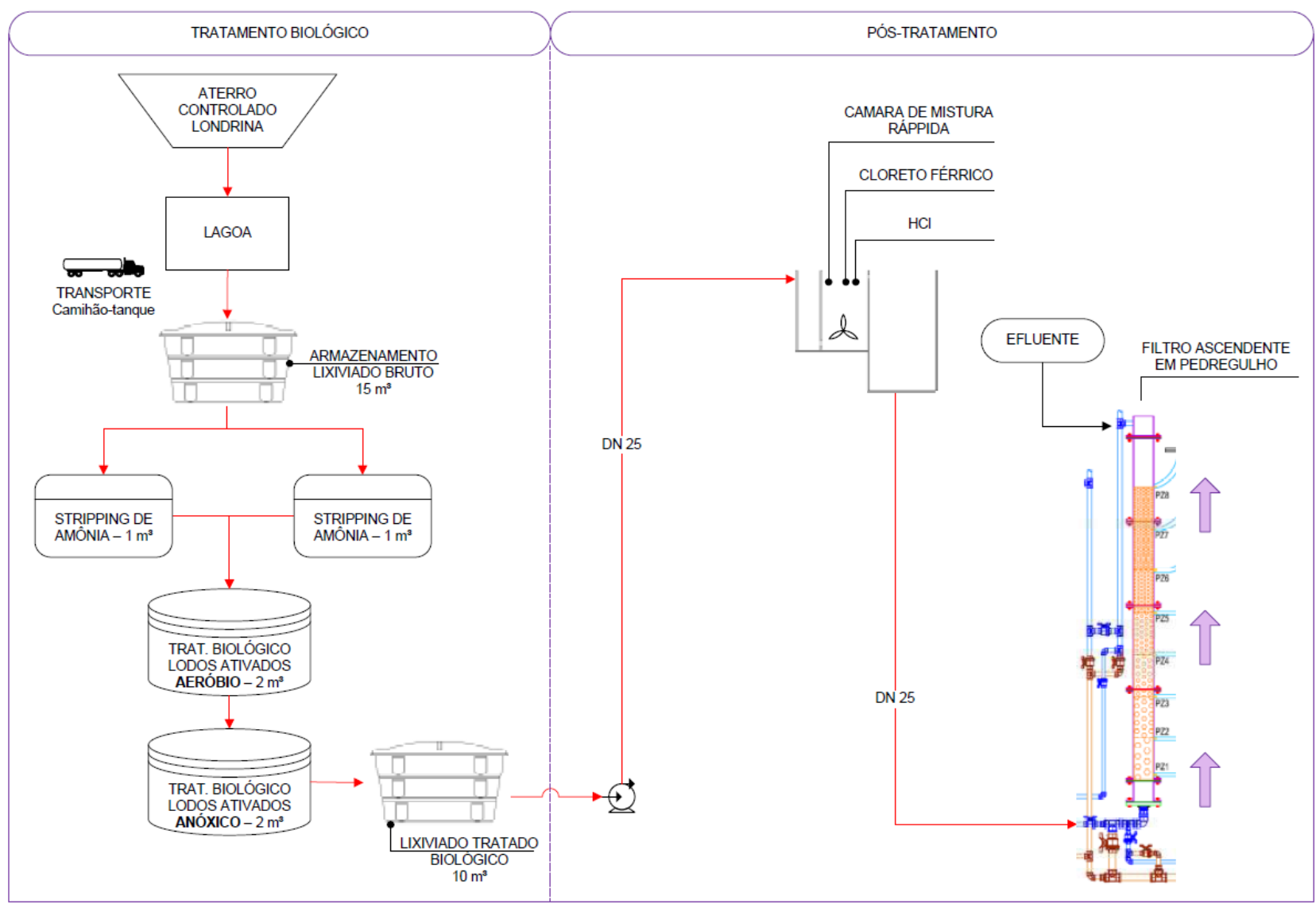

Figura 1 - Delineamento de pesquisa experimental

O lixiviado bruto foi proveniente do aterro controlado da cidade de LondrinaPR, o qual é caracterizado como estabilizado. Aproximadamente $10,0 \mathrm{~m}^{3}$ de lixiviado foram coletados através de um caminhão-tanque previamente limpo. Em seguida, procedeu-se armazenamento em tanque de $15,0 \mathrm{~m}^{3}$, localizado nas dependências do Laboratório de Saneamento da UEL.

$\mathrm{O}$ tratamento biológico do lixiviado foi realizado em duas etapas. $\mathrm{Na}$ primeira, empregou-se a técnica de Stripping de amônia em sistemas de bateladas sequenciais, realizada através de dois reatores com capacidade de $1 \mathrm{~m}^{3}$, constituídos por paletas giratórias de polietileno e aço inox com rotação de aproximadamente 5,5 rpm, 
para remoção parcial de $\mathrm{N}$-amoniacal após 20 dias de operação. Na segunda etapa, utilizou-se o tratamento biológico por lodos ativados, composto por fase aeróbica em reator com capacidade de $2 \mathrm{~m}^{3}$, com aeração realizada através de um compressor de ar e difusores construídos em PVC, seguido de fase anóxica com adição de etanol (fonte de carbono), dosado em função das concentrações de nitrito e nitrato para desnitrificação por via curta e consequente remoção da série nitrogenada.

No final de cada batelada do tratamento biológico, o efluente sobrenadante foi transferido para um tanque com capacidade de $10 \mathrm{~m}^{3}$.

A caracterização física e química do lixiviado bruto e tratado biologicamente foi realizada segundo parâmetros e métodos analíticos, descritos em APHA, AWWA, WEF (2005), conforme a Tabela 2.

Tabela 2 - Parâmetros e métodos utilizados

\begin{tabular}{c|c|c}
\hline Parâmetro & $\begin{array}{c}\text { REF. APHA, AWWA, WEF } \\
(2005)\end{array}$ & Método \\
\hline $\mathrm{pH}$ & Potenciométrico -4500 & Método potenciométrico \\
\hline Cor verdadeira $(\mathrm{uH})$ & $2120 \mathrm{C}$ & $\begin{array}{c}\text { Método espectrofotompetrico - filtrado } \\
\text { em membrana 0,45 } \mu \mathrm{m}\end{array}$ \\
\hline Cor aparente $(\mathrm{uH})$ & $2120 \mathrm{C}$ & Método espectrofotométrico \\
\hline $\mathrm{NKT}\left(\mathrm{mg} \mathrm{L}^{-1}\right)$ & $4500-\mathrm{Norg} \mathrm{B} \mathrm{e} \mathrm{C}$ & Micro-Kjeldhal \\
\hline $\mathrm{N}$-amoniacal $\left(\mathrm{mg} \mathrm{L}^{-1}\right)$ & $4500-\mathrm{NH}_{3} \mathrm{~B} \mathrm{e} \mathrm{C}$ & Destilação e titulação \\
\hline Nitrito $\left(\mathrm{mg} \mathrm{L}^{-1}\right)$ & $4500-\mathrm{NO}_{2} \mathrm{~B}$ & Método espectrofotométrico \\
\hline Nitrato $\left(\mathrm{mg} \mathrm{L}^{-1}\right)$ & - & $\begin{array}{c}\text { Método espectrofotométrico, de } \\
\text { acordo com Cataldo (1975) }\end{array}$ \\
\hline
\end{tabular}

O pós-tratamento do lixiviado tratado biologicamente foi realizado pela instalação piloto de filtração ascendente em pedregulho - IPFAP, a qual foi constituída por sistema de alimentação de lixiviado tratado biologicamente, unidade de mistura rápida, sistema de filtração ascendente em pedregulho e sistemas de descarga e lavagem de filtro, conforme apresentada na Figura 2. 


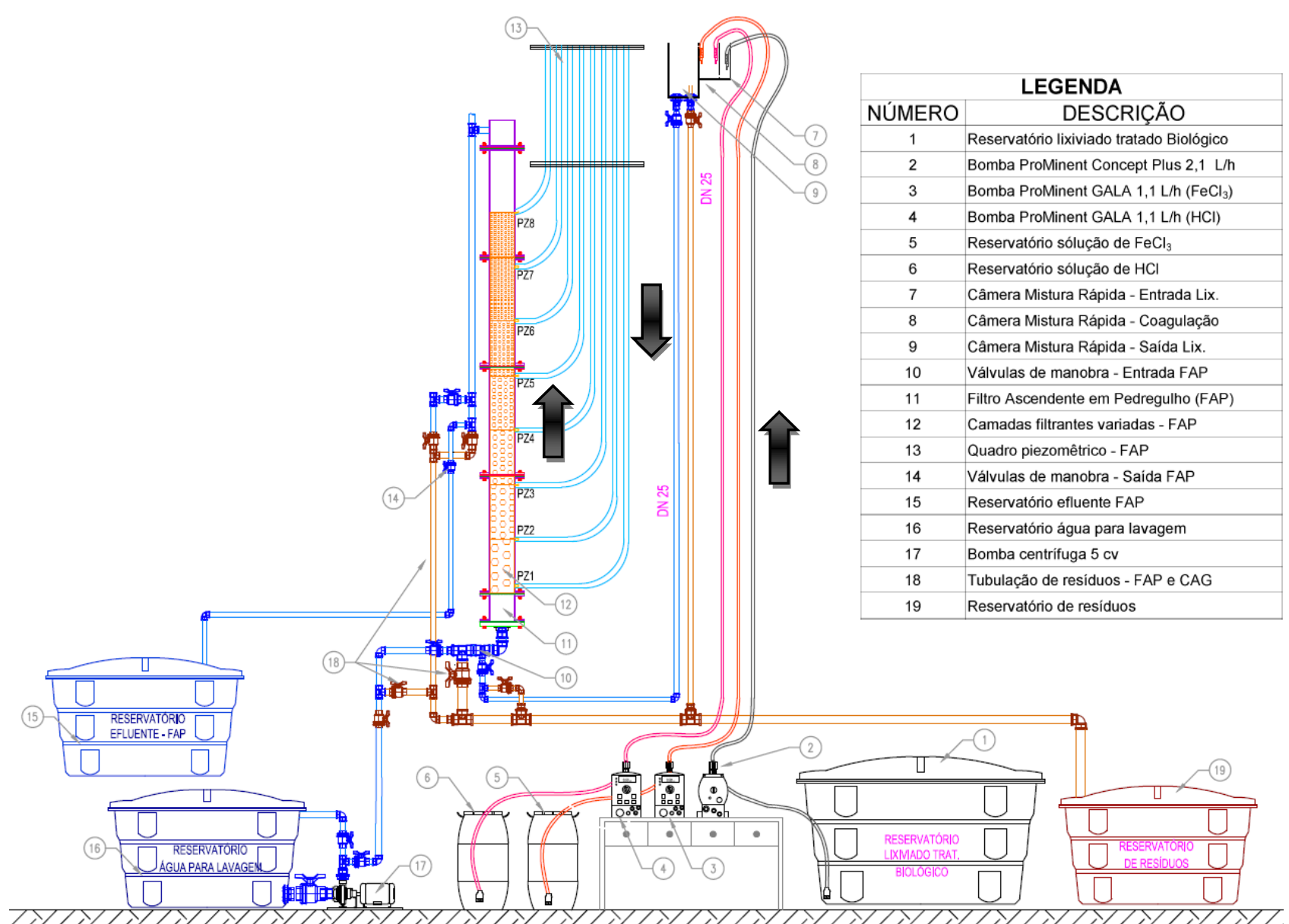

Figura 2 - Esquema da Instalação Piloto de Filtração Ascendente em Pedregulho (IPFAP)

O sistema de alimentação foi utilizado para recalcar o lixiviado tratado biologicamente para a câmara de mistura rápida - CMR, localizada a uma altura aproximada de 6,0 m, utilizando uma bomba dosadora eletromagnética (ProMinent Concept Plus) e mangueiras de sucção e racalque, com vazão de $12,0 \mathrm{~L} \mathrm{~h}^{-1}$.

A câmara de mistura rápida foi construída em acrílico e era constituída por 3 compartimentos interligados com orifícios de $25 \mathrm{~mm}$ de diâmetro. O primeiro compartimento foi utilizado para a entrada do lixiviado. O segundo compartimento foi projetado com as mesmas dimensões dos reatores estáticos do equipamento Jarteste, utilizado em ensaios preliminares para determinação das condições de coagulação química mais adequadas, e foi provida de um agitador com paleta de hélice naval (Fisaton - 713 D). Neste compartimento, ocorreu a mistura rápida propriamente dita com elevado gradiente de velocidade médio de mistura $\left(800 \mathrm{~s}^{-1}\right)$, tempo de mistura rápida (10 min) e 
adição de produtos químicos através de bombas dosadoras eletromagnéticas (ProMinent - 1601): cloreto férrico como coagulante químico e ácido clorídrico para ajuste do pH de coagulação.

O último compartimento foi constituído de duas tubulações de saída, sendo uma utilizada como extravasor e a outra, interligada diretamente ao fundo do filtro a fim de possibilitar a alimentação do filtro ascendente de pedregulho - FAP. Nessa tubulação foi feita uma derivação, provida de registros de manobras, para que fosse realizada a préoperação do sistema, desviando assim, a passagem da água coagulada pelo meio filtrante. Assim, somente após ajuste da vazão e da condição de coagulação química, iniciava-se a carreira de filtração.

As condições mais adequadas de coagulação química foram determinadas variando-se as dosagens de coagulante (cloreto férrico) e o pH de coagulação por meio de ensaios em reatores estáticos utilizando-se o equipamento Jarteste (Nova Ética 218/6LDBE). Este é composto de 6 jarros de acrílico transparente de 2 L, tacômetro digital para visualização da rotação (até 600 rpm \pm 2 \%), o que confere gradiente de velocidade de até $1.200 \mathrm{~s}-1$, dispositivo para aplicação simultânea de produtos químicos e coleta de água nos 6 jarros.

O filtro ascendente em pedregulho - FAP foi construído com chapas de acrílico de $6 \mathrm{~mm}$ de espessura e tinha uma dimensão em planta de $250 \times 250 \mathrm{~mm}$ e altura de $2810 \mathrm{~mm}$. O material granular foi composto por 6 subcamadas dispostas estratificadamente em ordem decrescente no sentido do fluxo, sendo 3 camadas de pedregulho de $300 \mathrm{~mm}$ de altura cada, com granulometria entre 4,80 a 25,4 mm, e 1 camada de pedrisco de $300 \mathrm{~mm}$ de altura, com granulometria de 2,40 a 4,80 mm, 1 camada de areia grossa de $300 \mathrm{~mm}$ de altura, com granulometria de 0,60 a 2,40 mm e a última camada de areia média-fina de $300 \mathrm{~mm}$ de altura com granulometria de 0,30 a 1,20 $\mathrm{mm}$ (Figura 3). 


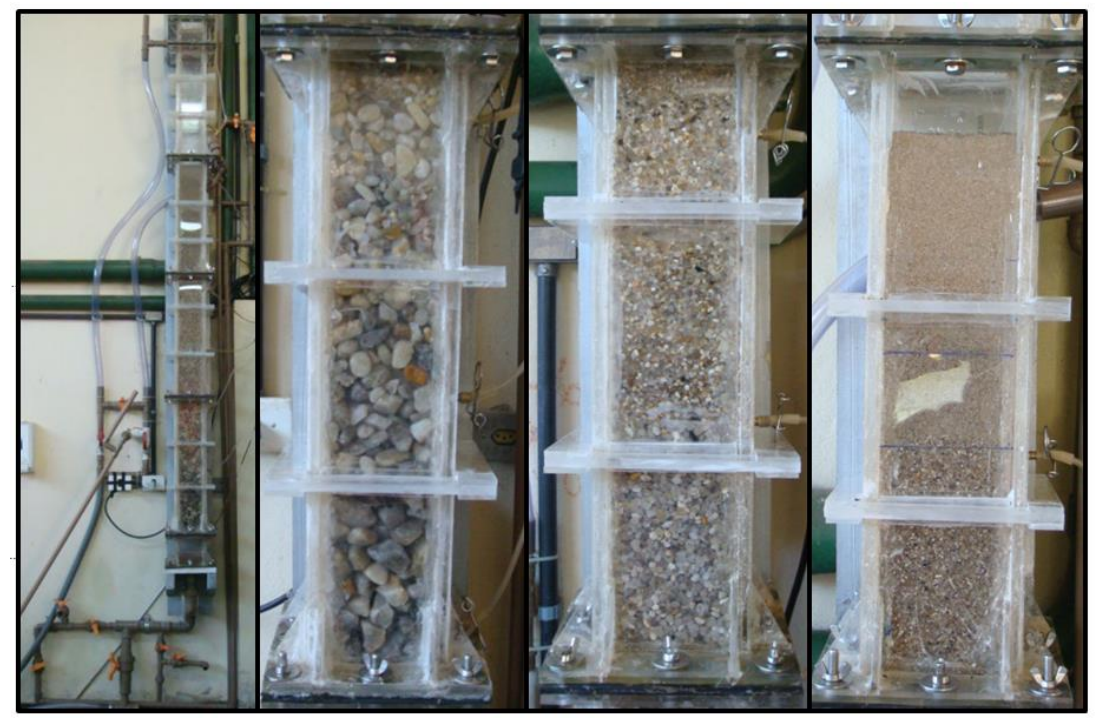

(a)

(b)

(c)

(d)

Figura 3 - (a): Instalação Piloto de Filtração Ascendente em Pedregulho (IPFAP) e material granular composto por 6 subcamadas. (b) 2 camadas de pedregulho $(9,5$ a 25,4 $\mathrm{mm}$ ), (c) 1 camada de pedregulho (4,8 a $9,5 \mathrm{~mm})$ e de pedrisco (2,4 a 4,8 $\mathrm{mm})$, (d) 1 camada de areia grossa $(0,6$ a 2,4 $\mathrm{mm}$ ) e areia médiafina $(0,3$ a $1,2 \mathrm{~mm})$

As descargas de fundo foram realizadas, por uma tubulação em PVC com diâmetro de $50 \mathrm{~mm}$, taxa média de $1935 \mathrm{~m}^{3} \mathrm{~m}^{2}$ dia $^{-1}$ e duração média de $45 \mathrm{~s}$. A lavagem do FAP foi realizada mediante aplicação de água tratada no sentido ascensional através de sistema elevatório e tubulação de PVC com diâmetro de $32 \mathrm{~mm}$, com taxa de lavagem $1240 \mathrm{~m}^{3} \mathrm{~m}^{-2} \mathrm{dia}^{-1}$ durante aproximadamente $10 \mathrm{~min}$.

Os ensaios preliminares realizados para pré-operação da instalação piloto de filtração ascendente em pedregulho - IPFAP incluíram aferição das válvulas, regularização das vazões de alimentação, calibração dos equipamentos e estabelecimento da sistemática de operação e coleta de dados. Após vários ensaios preliminares foi estabelecida a taxa de filtração de $15 \mathrm{~m}^{3} \mathrm{~m}^{-2} \mathrm{dia}^{-1}$.

Para controle operacional foi realizada coleta de amostras após a CMR a cada 15 min para o monitoramento do pH de coagulação química. Para avaliação da eficiência do sistema, iniciou-se a coleta das amostras do efluente filtrado a cada 15 min na primeira hora e a cada 30 min até o final da carreira de filtração.

Os parâmetros físicos e químicos avaliados foram vazão, $\mathrm{pH}$, perda de carga na camada filtrante e cor aparente. 
Os valores da caracterização físico-química do lixiviado bruto e tratado por stripping de amônia e biológico são apresentados na Tabela 3. Os resultados encontrados neste trabalho diferem dos obtidos por Kawahigashi (2012) e Felici (2010), pois no momento da coleta a lagoa encontrava-se sob aeração, alterando assim as características do lixiviado de estudo. Entretanto, o mesmo apresentou características de um lixiviado já estabilizado.

Tabela 3 - Caracterização físico-química do lixiviado

\begin{tabular}{|c|c|c|c|c|}
\hline \multirow{2}{*}{ Parâmetro } & \multirow{2}{*}{ UNIDADE } & \multicolumn{2}{|c|}{ LIXIVIADO } & \multirow{2}{*}{ REMOÇÃO (\%) } \\
\hline & & BRUTO & BIOLÓGICO & \\
\hline $\mathrm{pH}$ & & $\overline{8,9}$ & 8,5 & - \\
\hline Cor Verdadeira & $\mathrm{uH}$ & 4078 & 3968 & 3 \\
\hline Cor Aparente & $\mathrm{uH}$ & 4684 & 4290 & 11 \\
\hline $\mathrm{DQO}$ & $\mathrm{mg} \mathrm{O}_{2} \cdot \mathrm{L}^{-1}$ & 1466 & 1101 & 25 \\
\hline NKT & $\mathrm{mg} \mathrm{N}-\mathrm{NH}_{3} \mathrm{~L}^{-1}$ & 187,8 & 109,5 & 42 \\
\hline $\mathrm{N}$-amoniacal & 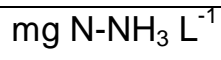 & 71,7 & 7,3 & 89 \\
\hline Nitrito & $\mathrm{mg} \mathrm{N}-\mathrm{NO}_{2} \mathrm{~L}^{-1}$ & 65,2 & 2,3 & 96 \\
\hline Nitrato & $\mathrm{mg} \mathrm{N}-\mathrm{NO}_{2} \mathrm{~L}^{-1}$ & 280,9 & 3,9 & 98 \\
\hline Cloreto & $\mathrm{mg} \mathrm{L}^{-1}$ & 2153 & 2393 & - \\
\hline
\end{tabular}

Pode-se observar que após o tratamento por stripping de amônia seguido do tratamento biológico por lodos ativados a remoção de NKT foi da ordem de $42 \%, \mathrm{~N}$ amoniacal de $89 \%$, nitrito de $96 \%$ e nitrato de $98 \%$, eliminando assim grande parte do nitrogênio no lixiviado. No entanto, a matéria orgânica recalcitrante ainda permanece no lixiviado, evidenciada pela elevada cor aparente e verdadeira e concentração de DQO, o que comprova a necessidade do pós-tratamento.

As dosagens de produtos químicos utilizados na IPFAP foram obtidos do diagrama de coagulação química realizado em Jarteste por POZZETTI et. al. (2013): dosagem de $400 \mathrm{mg} \mathrm{L}^{-1}$ de $\mathrm{Fe} \mathrm{e} \mathrm{pH}$ 4, ajustado pela dosagem $630 \mathrm{mg} \mathrm{L}^{-1}$ de $\mathrm{HCl}$, obtendo-se eficiência de $98,6 \%$ de remoção para cor verdadeira. 
Assim, com base na taxa de filtração de $15 \mathrm{~m}^{3} \mathrm{~m}^{-2} \mathrm{dia}^{-1}$ e nas vazões estabelecidas para as dosagens de $\mathrm{Fe}\left(0,50 \mathrm{~L} \mathrm{~h}^{-1}\right)$ e $\mathrm{HCL}\left(0,50 \mathrm{~L} \mathrm{~h}^{-1}\right)$, preparou-se as soluções de dosagem dos produtos químicos, com concentrações de $9,68 \mathrm{~g} \mathrm{~L}^{-1}$ de $\mathrm{FeCl}_{3} \mathrm{e}$ de $15,25 \mathrm{~g} \mathrm{~L}^{-1}$ de $\mathrm{HCl}$.

A partir de ensaios preliminares, foram definidas: perda de carga limite do FAP de $120 \mathrm{~cm}$ e número de descargas de fundo de intermediárias (DFIs) igual a 4, a fim de prolongar a carreira de filtração, sendo a primeira DFI com $30 \mathrm{~cm}$ de perda de carga ( $1^{\circ}$ ciclo), a $2^{\circ} \mathrm{DFI}$ com $60 \mathrm{~cm}$ ( $2^{\circ}$ ciclo), a $3^{\circ} \mathrm{DFI}$ com 90 ( $3^{\circ}$ ciclo) e a última DFI com 120 $\mathrm{cm}\left(4^{\circ}\right.$ ciclo), finalizando assim a carreira de filtração.

A pré-operação do sistema iniciava-se um dia antes da operação para que ocorresse a regularização da vazão de lixiviado. Em seguida, as bombas de produtos químicos $\left(\mathrm{FeCl}_{3}\right.$ e $\left.\mathrm{HCl}\right)$ eram acionadas, e a partir desta etapa, era realizado o monitoramento / ajuste do pH de coagulação até atingir e estabilizar o pH em torno de 4,0, quando iniciava-se a operação.

Após o tempo necessário para enchimento do FAP e substituição total do líquido (120 min) foi coletada a primeira amostra, cuja eficiência de remoção de cor aparente foi de $99,6 \%$, resultando em um residual de $15,9 \mathrm{uH}$, conforme observado nas Figuras 4 e 6.

Ao longo do primeiro ciclo de filtração, $\mathrm{O} \mathrm{pH}$ manteve-se praticamente constante $(\mathrm{pH}=4,0)$ e a cor aparente residual variou de 15,9 a 23,8 uH (Figura 5). A frente de impurezas foi de $180 \mathrm{~cm}$, medida a partir da base do filtro (Figura 6). A perda de carga limite do $1^{\circ}$ ciclo $(30,0 \mathrm{~cm})$ foi atingida após $6,45 \mathrm{~h}$ de operação (Figura 7$)$.

Atingida a perda de carga limite, o lixiviado coagulado foi desviado e pela abertura do dreno, deu-se início à primeira DFI do FAP, que teve duração de $34 \mathrm{~s}$ e um volume de 17,50 L, resultando em uma taxa de $2335 \mathrm{~m}^{3} \mathrm{~m}^{2} \mathrm{dia}^{-1}$. Logo em seguida, iniciou-se o $2^{\circ}$ ciclo de operação, e assim sucessivamente. $O$ tempo de enchimento do filtro foi de aproximadamente $2,0 \mathrm{~h}$ após cada DFI, conforme ilustra a Figura 7 , devido à baixa taxa de filtração $\left(15 \mathrm{~m}^{3} \mathrm{~m}^{2}\right.$ dia $\left.^{-1}\right)$ aplicada.

A duração total da carreira de filtração foi de $24,0 \mathrm{~h}$, na qual a eficiência de remoção variou de $99,6 \%$, no início da carreira, a 99,1\%, no final da carreira, resultando 
em um residual de cor aparente de 15,9 uH e 37,9 uH, respectivamente (Figura 5). $\mathrm{O}$ aumento da cor residual ocorreu devido ao acúmulo gradual de impurezas nas camadas filtrantes, contribuindo para a ocorrência do transpasse.

Pela Figura 6, percebe-se que o caminhamento da frente de impurezas nos 4 ciclos de operação foi praticamente semelhante, ocorrendo uma pequena variação durante a operação, em virtude do aumento da perda de carga e da retenção de impurezas nas camadas filtrantes a cada ciclo de operação, principalmente na camada de areia, pois observou-se que os flocos ficavam retidos nesta camada mesmo após as DFls.

As três primeiras DFls ocorreram conforme a programação, com 30, 60 e 90 cm de perda de carga, no entanto, a última não atingiu os $120 \mathrm{~cm}$ de perda de carga pois ocorreu transpasse dos flocos, ilustrado na Figura 4, encerrando assim a carreira de filtração com $46 \mathrm{~cm}$ de perda de carga.

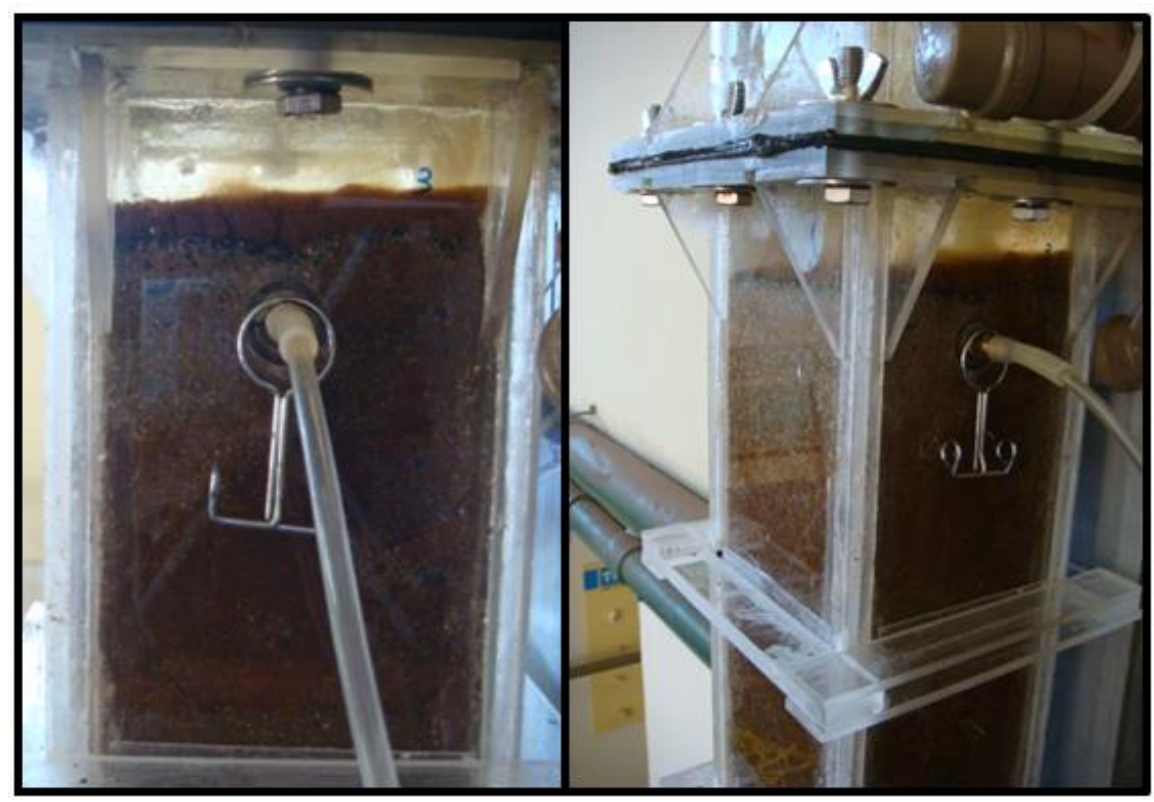

Figura 4 - Transpasse de flocos no último ciclo da carreira de filtração após 24 h de operação 


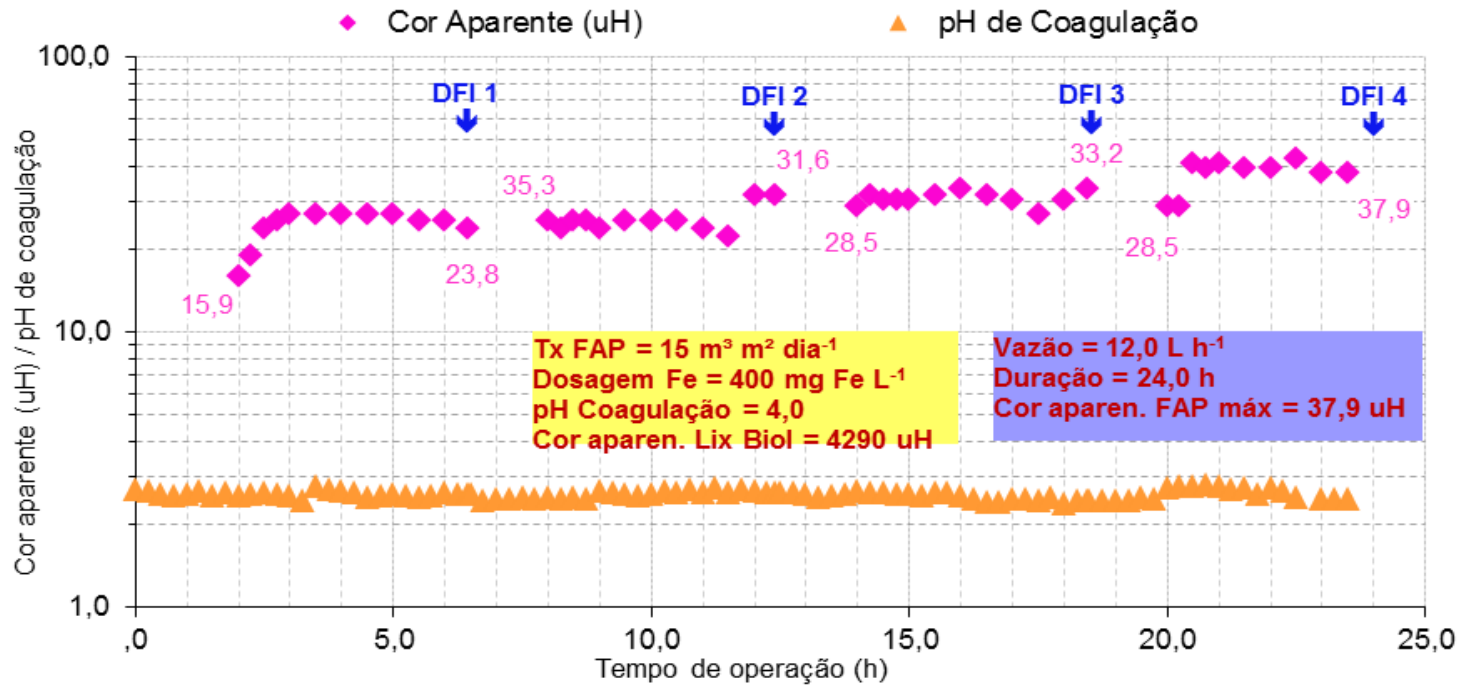

Figura 5 - Variação dos valores de pH de coagulação e de cor aparente do lixiviado tratado pela filtração ascendente em pedregulho em função do tempo de operação.

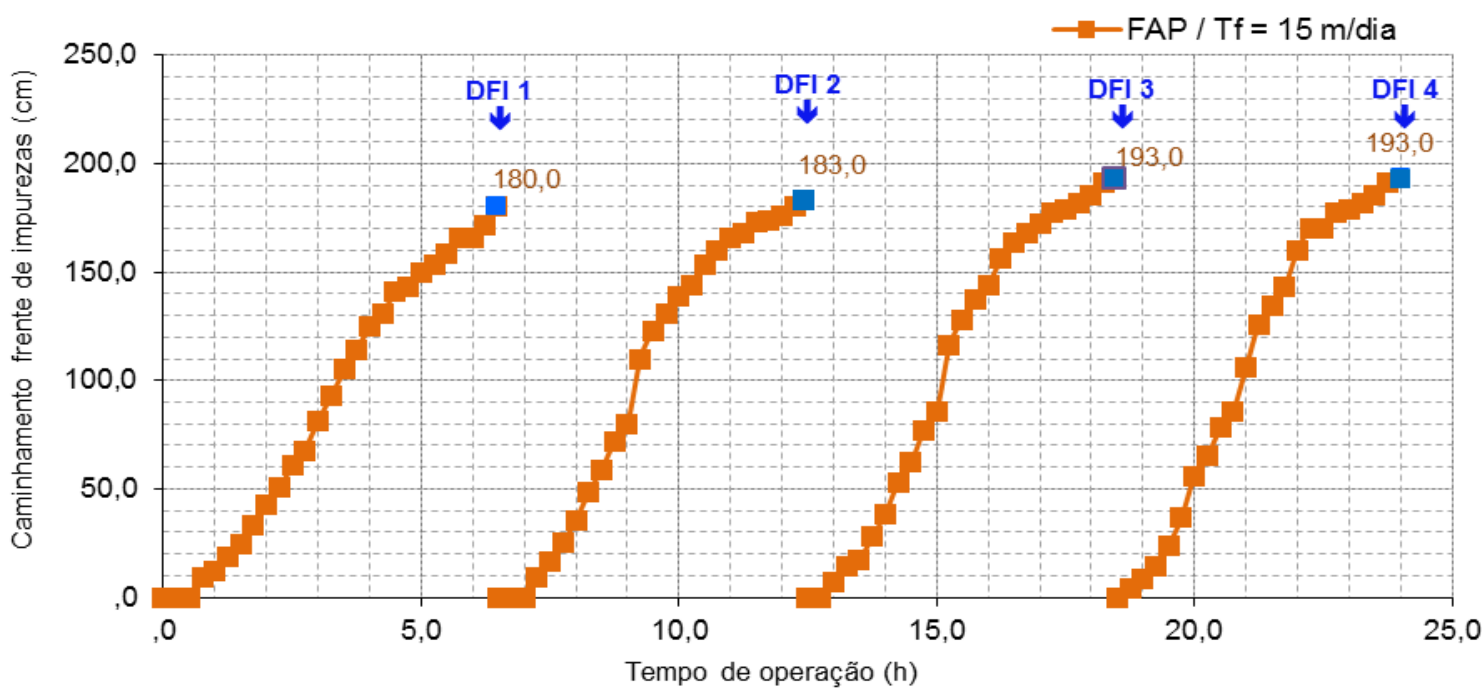

Figura 6 - Caminhamento da frente de impurezas ao longo do meio granular em função do tempo de operação. 


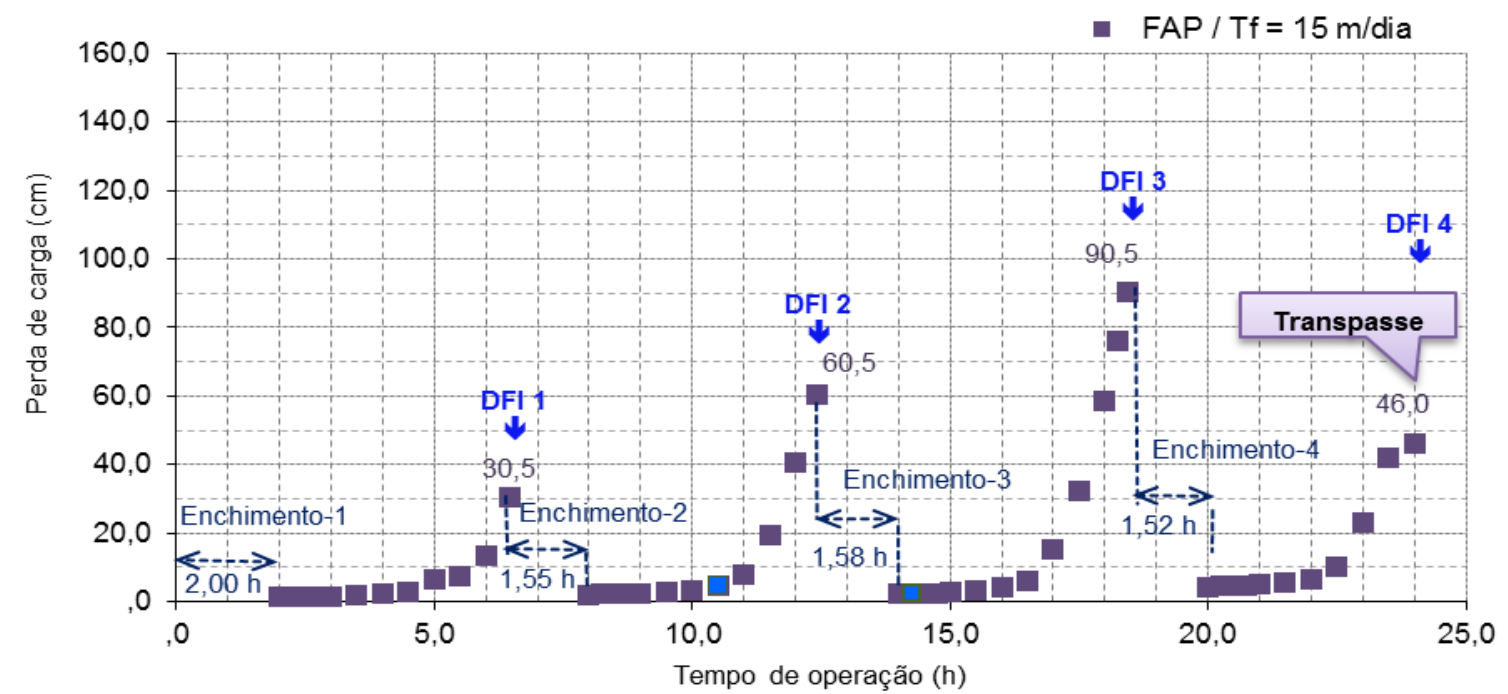

Figura 7 - Variação da perda de carga em função do tempo de operação / tempo de enchimento entre as carreiras intermediárias.

\section{CONCLUSÃO}

A filtração direta ascendente em pedregulho apresentou potencial para aplicação como pós-tratamento em escoamento contínuo de lixiviado tratado por stripping de amônia e processos biológicos, apresentando uma eficiência de remoção de cor aparente de $99,6 \%$ a $99,1 \%$, resultando em valores residuais entre 15,9 e $37,9 \mathrm{uH}$, respectivamente.

Há necessidade de continuidade dos estudos quanto aos demais parâmetros considerando as legislações vigentes e a diminuição dos impactos ambientais e dos riscos à saúde pública.

\section{REFERÊNCIA}

APHA, AWWA, WEF. Standard Methods for the Examination of Water and Wastewater. American Public Health Association (APHA), American Water Works Association (AWWA), Water Environment Federation (WEF). 21를 Edição, 2005. 
CEZAR, M.C.M.; CARVALHO, R.P.M.; BRANDÃO, C.C.S. (2000). Efeito da coagulação química na (pré) filtração em pedregulho de águas com presença de algas, e seu potencial como pré-tratamento para a filtração rápida descendente. / Apresentado ao $21^{\circ}$.Congresso Interamericano de Engenharia Sanitária e Ambiental, Porto Alegre-RS.

DI BERNARDO, L. Método e técnicas de tratamento de água. Rio de Janeiro: ABES, 1993. v.2.

DINIZ, D. T. L. Remoção de nitrogênio amoniacal de lixiviado de aterro de resíduos sólidos por precipitação química com formação de estruvita. 2010. Dissertação (Mestrado em Tecnologia Ambiental e Recursos Hídricos) - Faculdade de Tecnologia de Brasília, 2010.

FELICI, E. M. Coagulação-floculação-sedimentação como pós-tratamento de efluente de sistema biológico em batelada aplicado a lixiviado de aterro de resíduos sólidos urbanos. 2010. Dissertação (Mestrado em Engenharia de Edificações e Saneamento) - Universidade Estadual de Londrina. Londrina, 2010.

GUSMÃO, P. T. R. (2001). Utilização de Filtração direta ascendente como prétratamento para tratamento de água de abastecimento. São Carlos. 335 p. Tese de doutorado - Escola de Engenharia de São Carlos, Universidade de São Paulo.

HOSSAKA, A. L. (2008). Tratamento biológico de lixiviados de aterro sanitário, utilizando como pré-tratamento a remoção parcial de $\mathrm{N}$-amoniacal por stripping. Dissertação (Mestrado em Engenharia de Edificações e Saneamento) - Universidade Estadual de Londrina. Centro de Tecnologia e Urbanismo. Londrina. 2008.

KAWAHIGASHI, F. Aplicabilidade do pós-tratamento de lixiviado de aterro sanitário por adsorção em carvão ativado granular e avaliação ecotoxicológica. Dissertação (Mestrado em Engenharia de Edificações e Saneamento) - Universidade Estadual de Londrina. Centro de Tecnologia e Urbanismo. Londrina. 2012.

KURODA, E. K. Avaliação da filtração direta ascendente em pedregulho como prétratamento em sistemas de duplas filtração. Dissertação (Mestrado). Escola de Engenharia de São Carlos. Universidade de São Paulo. São Carlos. 2002. 
KURODA, E. K. (2006). Remoção de células e subprodutos de Microcystis spp. por dupla filtração, oxidação e adsorção. São Carlos, 2006. 233 p. Tese (Doutorado) Escola de Engenharia de São Carlos, Universidade de São Paulo.

MARINGONDA, J. A. Remoção de nitrogênio de lixiviado de aterros de resíduos sólidos urbanos empregando sistema de lodos ativados, composto por reator anóxico e aeróbio em série. Dissertação Mestrado. Universidade Estadual de Londrina, 2008.

MEGDA, C. R (1999). Filtração direta ascendente em pedregulho como prétratamento à filtração rápida descendente. São Carlos. 170 p. Dissertação (mestrado) - Escola de Engenharia de São Carlos, Universidade de São Paulo.

POZZETTI, J. D. C.; MENDES, M. B.; FUJII, E. H.; KASHIGOE, A. S. H.; COUTROUTSOS, Y. N.; KURODA, E. K. Coagulação química de lixiviado estabilizado de aterro sanitário. IN: CONGRESSO BRASILEIRO DE ENGENHARIA SANITÁRIA E AMBIENTAL, 27, 2013. Goiânia - GO. ABES.

RENOU, S.; GIVAUDAN J. G.; POULAIN, S.; DIRASSOUYAN, F.; MOULIN, P. Landfill leachate treatment: Review and opportunity. Journal of Hazardous Materials, v. 150, p 468-493, 2008.

ROERS, F. Tratamento físico-químico de lixiviado de aterro sanitário por filtração direta ascendente. Dissertação Mestrado. Universidade Federal de Santa Catarina, 2007. 